\title{
SIRT1 promotes pulmonary artery endothelial cell proliferation by targeting the Akt signaling pathway
}

\author{
LIANDONG XI $^{1^{*}}$, LIN RUAN $^{2 *}$, XIAOGUANG YAO ${ }^{3,4}$, DONG ZHANG $^{3}$, \\ HONGWEI YUAN $^{5}$, QIANG LI ${ }^{3,6}$ and CUIHUAN YAN ${ }^{3,7}$ \\ ${ }^{1}$ Department of Cardiovascular, Beijing Miyun Hospital Affiliated Capital Medical University, Beijing 101500; \\ ${ }^{2}$ Department of Nephrology, The First Hospital of Hebei Medical University, Shijiazhuang, Hebei 050051; \\ ${ }^{3}$ Hebei Key Laboratory of Integrative Medicine on Liver-Kidney Patterns, Institute of Integrative Medicine, College of \\ Integrative Medicine; ${ }^{4}$ Department of Surgery, Hebei University of Chinese Medicine, Shijiazhuang, Hebei 050200; \\ ${ }^{5}$ The Third Cardiovascular Department, The Second Affiliated Hospital of Tianjin University of Traditional \\ Chinese Medicine, Tianjin 300193; Departments of ${ }^{6}$ Medical Imaging and ${ }^{7}$ Internal Medicine, \\ Hebei University of Chinese Medicine, Shijiazhuang, Hebei 050200; P.R. China
}

Received March 7, 2020; Accepted July 10, 2020

DOI: $10.3892 /$ etm.2020.9309

\begin{abstract}
Pulmonary arterial hypertension (PAH) is a disease characterized by a progressive increase in pulmonary vascular resistance and obliterative pulmonary vascular remodeling; however, the pathogenesis of the disease is not completely understood. Sirtuin 1 (SIRT1) is a histone deacetylase involved in cell survival and metabolism. The present study explored the potential role of SIRT1 in human pulmonary arterial endothelial cells (HPAECs) under hypoxic conditions. In vitro HPAECs were cultured and exposed to hypoxic conditions. Subsequently, SIRT1 expression levels were measured via western blotting, the generation of reactive oxygen species (ROS) was evaluated, and the interaction between SIRT1 and Akt was assessed via reverse transcription-quantitative PCR and western blotting. In addition, the effects of SIRT1 on cell proliferation and apoptosis were also investigated. The results indicated that hypoxia induced SIRT1 expression in pulmonary arterial endothelial cells, which may be associated with ROS generation. SIRT1 expression activated the Akt signaling pathway, which increased the expression levels of Bcl-2 and hypoxia-inducible factor-1 in HPAECs. Moreover, SIRT1
\end{abstract}

Correspondence to: Dr Qiang Li or Dr Cuihuan Yan, Hebei Key Laboratory of Integrative Medicine on Liver-Kidney Patterns, Institute of Integrative Medicine, College of Integrative Medicine, Hebei University of Chinese Medicine, 3 Xingyuan Road, Shijiazhuang, Hebei 050200, P.R. China

E-mail: lijinyi139@163.com

E-mail: yancuihuan1976@126.com

${ }^{*}$ Contributed equally

Key words: hypoxia, sirtuin 1, Akt signaling pathway, apoptosis, reactive oxygen species promoted HPAEC proliferation and inhibited HPAEC apoptosis. ROS generation enhanced the SIRT1/Akt axis, which was essential for epithelial cell injury under hypoxic conditions. Therefore, blocking SIRT1 may reduce hypoxia-induced pathological damage in HPAECs.

\section{Introduction}

Pulmonary arterial hypertension (PAH) is a disease of the small pulmonary arteries that is characterized by a progressive increase in pulmonary vascular resistance and obliterative pulmonary vascular remodeling, leading to uncompensated right heart failure, and ultimately, death (1). The histopathological features of PAH include intima and media thickness, muscularization of distal pulmonary arteries, vascular occlusion and complex plexiform lesions (2). Although the pathogenesis of PAH is not completely understood, it has been reported that the genetic change resulting in endothelial dysfunction is an important contributing factor $(2,3)$. Previous studies have revealed that bone morphogenetic protein type II receptor (BMPR2) mutations serve an important role in PAH pathogenesis via the Smad and transforming growth factor- $\beta$ signaling pathways (4-6). However, as PAH is not penetrant, BMPR2 mutations alone may not be sufficient to cause disease, therefore, other genetic and/or non-genetic factors may serve as a 'second hit' to trigger PAH pathology (7), including inflammation and chronic hypoxia. Chronic hypoxia may serve a key role in the pathogenesis of $\mathrm{PAH}$ via pathological alterations to endothelial cells in the vascular system $(8,9)$. Chronic hypoxia can also induce the generation of reactive oxygen species (ROS) in tissues, which triggers epigenetic changes and induces dysregulation of various signaling pathways in endothelial cells (10).

As an epigenetic factor, Sirtuin 1 (SIRT1) may respond to $\operatorname{ROS}(11,12)$. SIRT1 is expressed in the nucleus and cytoplasm of multiple tissues, acting as a histone deacetylase that participates in cell apoptosis, survival and proliferation (13). In 
a previous study on prostate cancer, Ruan et al (12) suggested that the generation of ROS can increase the expression level of SIRT1. Moreover, other studies have reported that SIRT1 expression is increased in endothelial and smooth muscle cells in PAH $(14,15)$, but SIRT1-induced pathogenic alterations have not been explored further. Therefore, the present study investigated SIRT1 expression in hypoxia-induced arterial endothelial cells. SIRT1 expression was significantly increased in response to ROS generation, and SIRT1 promoted human arterial endothelial cell proliferation, but inhibited apoptosis. Furthermore, the results indicated that the SIRT1 inhibitor could decrease the activity of the Akt signaling pathway, which facilitates PAH development.

\section{Materials and methods}

Cell culture. Human pulmonary arterial endothelial cells (HPAECs; cat. no. PCS-100-022; American Type Culture Collection) were cultured in endothelial cell medium (ScienCell Research Laboratories, Inc.) supplemented with 10\% FBS (Hyclone; Cytiva), $100 \mathrm{U} / \mathrm{ml}$ penicillin (Invitrogen; Thermo Fisher Scientific, Inc.) and $100 \mathrm{U} / \mathrm{ml}$ streptomycin (Invitrogen; Thermo Fisher Scientific, Inc.) at $37^{\circ} \mathrm{C}$ with $5 \% \mathrm{CO}_{2}$. Cells up to passage 4 were used for subsequent experiments.

Cells $\left(5 \times 10^{3}\right.$ cells/well in 96-well plates) were treated with $0.4 \mu \mathrm{M}$ SIRT1 antagonist (EX-527; dissolved in DMSO; Selleck Chemicals) (16), $4 \mu \mathrm{M}$ SIRT1 activator (SRT1720; dissolved in DMSO (12); Selleck Chemicals) and $10 \mu \mathrm{M}$ Akt antagonist (mk2206; dissolved in DMSO; Selleck Chemicals) (17). In addition, cells were treated with $1 \mathrm{mM}$ hydrogen peroxide $\left(\mathrm{H}_{2} \mathrm{O}_{2}\right.$; cat. no. H1009; Sigma-Aldrich; Merck KGaA) and 5 mM N-acetylcysteine (NAC; cat. no. ST1546; Beyotime Institute of Biotechnology) (18). The control group was treated with the same volume of DMSO. During the treatment, cells were maintained at $37^{\circ} \mathrm{C}$ for $72 \mathrm{~h}$.

Cell hypoxia experiments in vitro. To induce in vitro hypoxic conditions, HPAECs were placed in a hypoxic chamber $(10 \%$ $\mathrm{O}_{2}$ and $5 \% \mathrm{CO}_{2}$ ) for $72 \mathrm{~h}$ at $37^{\circ} \mathrm{C}$. Control cells were maintained under standard culture conditions $\left(37^{\circ} \mathrm{C} ; 21 \% \mathrm{O}_{2}\right.$ and $\left.5 \% \mathrm{CO}_{2}\right)$ for $72 \mathrm{~h}(19,20)$.

SIRT1 activity assay. To evaluate SIRT1 activity, a fluorescent activity kit for SIRT1 (SIRT1 Activity Assay kit (Fluorometric); cat. no. ab156065; Abcam) was used according to the manufacturer's protocol. The results were read at a fluorescent emission of $460 \mathrm{~nm}$ using a multimode plate reader (Thermo Fisher Scientific, Inc.).

Western blotting. Cells were collected and then centrifugated at $500 \mathrm{x} g$ for $5 \mathrm{~min}$ at room temperature and media was aspirated. Subsequently, the cell pellets were washed with ice-cold PBS, centrifuged at $500 \mathrm{xg}$ for $5 \mathrm{~min}$ at $4^{\circ} \mathrm{C}$ and supernatant was aspirated. Cell pellets were lysed in RIPA buffer (cat. no. P0013B; Beyotime Institute of Biotechnology) containing proteinase inhibitors (cat. no. P1006; Beyotime Institute of Biotechnology). Equal amounts of protein $(20 \mu \mathrm{g} /$ lane $)$ were separated via $8-10 \%$ SDS-PAGE and electrotransferred onto PVDF membranes (EMD Millipore). The membranes were blocked with 5\% BSA (cat. no. ST023-50 g; Beyotime Institute of Biotechnology) for
$1 \mathrm{~h}$ at room temperature. Following blocking, membranes were incubated at $4^{\circ} \mathrm{C}$ overnight with primary antibodies $(1: 3,000)$ targeted against: Anti-SIRT1 (rabbit; cat. no. ab189494; Abcam), anti-Akt (rabbit; cat. no. 9272; Cell Signaling Technology, Inc.), anti-phosphorylated (p)-Akt (rabbit; cat. no. P00024-5; Boster Biological Technology), anti-Bcl-2 (rabbit; cat. no. ab59348; Abcam), anti-hypoxia-inducible factor-1 (HIF-1; rabbit; cat. no. ab82832; Abcam) and anti-GAPDH (mouse; cat. no. sc-32233; Santa Cruz Biotechnology, Inc.). Subsequently, the membranes were incubated with HRP-conjugated anti-rabbit $\operatorname{IgG}(1: 3,000$; cat. no. ab205718; Abcam) or HRP-conjugated anti-mouse IgG secondary antibody (1:3,000; cat. no. ab205719; Abcam) at room temperature for $1 \mathrm{~h}$. Protein bands were visualized using the Western Bright ECL kit (Bio-Rad Laboratories, Inc.). GAPDH was used as the loading control. The protein expression levels were quantified with ImageJ software (version 1.8.0; National Institutes of Health).

Reverse transcription-quantitative PCR. Total RNA was extracted from cells using TRIzol ${ }^{\circledR}$ (Beyotime Institute of Biotechnology). Total RNA (500 ng) was reverse transcribed into cDNA using a SuperScript III Reverse Transcriptase kit (cat. no. 18080093; Invitrogen; Thermo Fisher Scientific, Inc.) at $50^{\circ} \mathrm{C}$ for $50 \mathrm{~min}$ and $85^{\circ} \mathrm{C}$ for $5 \mathrm{~min}$. Subsequently, qPCR was performed using SYBR Green (cat. no. 4309155; Thermo Fisher Scientific, Inc.) according to the manufacturer's protocol on the ABI PRISM 7500 real-time PCR system (Applied Biosystems; Thermo Fisher Scientific, Inc.). The following primers were used for qPCR: GAPDH forward, 5'-TGTGGGCATCAATGGATTTGG-3' and reverse, 5'-ACA CCATGTATTCCGGGTCAAT-3'; and SIRT1 forward, 5'-TAGCCTTGTCAGATAAGGAAGGA-3' and reverse, 5'-ACAGCTTCACAGTCAACTTTGT-3'. The following thermocycling conditions were used for the qPCR: Initial denaturation for $10 \mathrm{~min}$ at $95^{\circ} \mathrm{C} ; 40$ cycles of $15 \mathrm{sec}$ at $95^{\circ} \mathrm{C}$ for denaturation, $30 \mathrm{sec}$ at an annealing temperature of $60^{\circ} \mathrm{C}$ and a $30 \mathrm{sec}$ extension at $72^{\circ} \mathrm{C}$. mRNA expression levels were quantified using the $2^{-\Delta \Delta \mathrm{Cq}}$ method and normalized to the internal reference gene GAPDH (21).

Nitroblue tetrazolium (NBT) assay. An NBT assay kit (Sigma-Aldrich; Merck KGaA) was used to assess ROS generation. Briefly, cells were seeded $\left(5 \times 10^{3}\right.$ cells/well) into 96-well plates and maintained under hypoxic or normal conditions for $72 \mathrm{~h}$. Subsequently, the plates were washed with PBS to remove cell debris. Cells were counted and incubated with $0.1 \% \mathrm{NBT}$ for $90 \mathrm{~min}$ at $37^{\circ} \mathrm{C}$. Cells were collected, sonicated ( $20 \mathrm{kHz} / \mathrm{s}, 30 \mathrm{sec}$, on ice) and dissolved in acetic acid. The absorbance of each well was measured at a wavelength of $560 \mathrm{~nm}$ using a multiple plate reader.

Cell apoptosis assay. Flow cytometry was performed to evaluate cell apoptosis in vitro. After treatment, cells were collected, washed with PBS and resuspended in $500 \mu 1$ binding buffer containing $5 \mu \mathrm{l}$ annexin V-fluorescein isothiocyanate and $10 \mu \mathrm{l}$ propidium iodide (cat. no. ANNEX300F; Bio-Rad Laboratories, Inc.). Following incubation for $30 \mathrm{~min}$ in the dark at room temperature, cell apoptosis was assessed using a FACScan flow cytometer (BD Biosciences). 

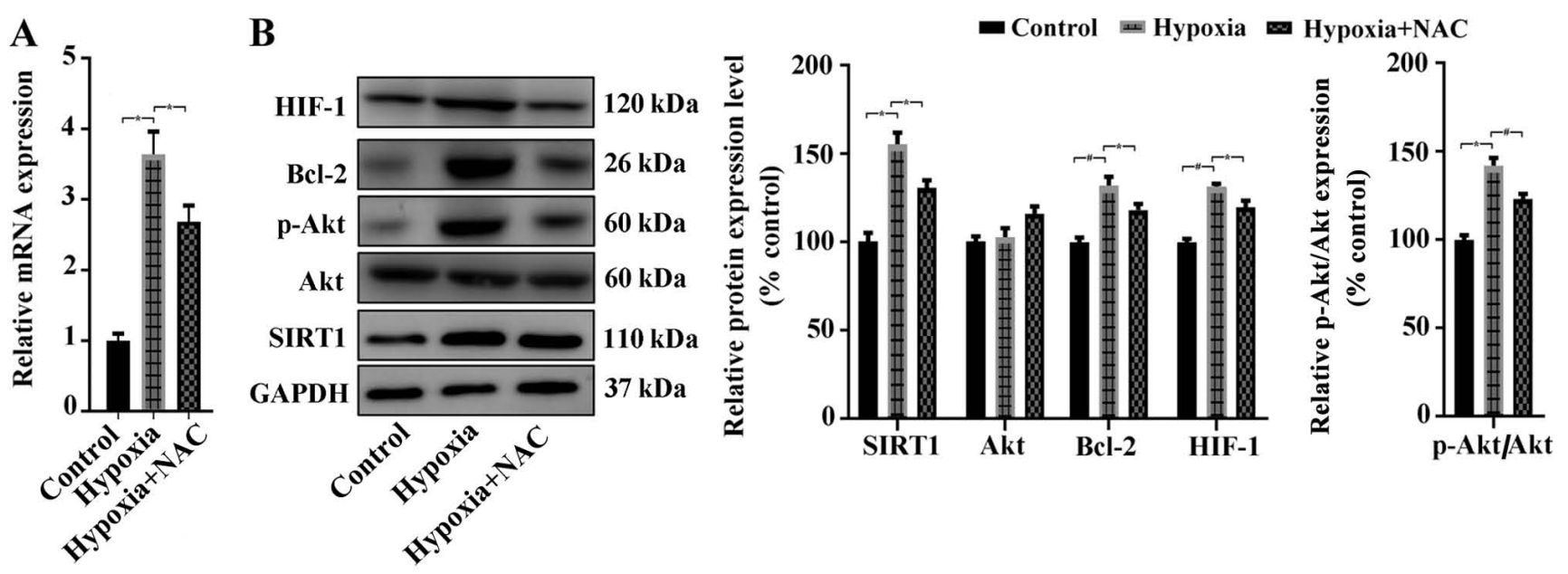

Figure 1. Hypoxia increases SIRT1 expression and activates the Akt signaling pathway, which can be alleviated by anti-reactive oxygen species reagent (NAC). (A) Compared with the control group, SIRT1 mRNA expression levels were increased after hypoxia treatment, which was reversed by NAC. (B) SIRT1 protein expression increased after hypoxia treatment compared with the control group. Moreover, compared with the control group, Akt phosphorylation was increased in cells under hypoxic conditions, but inhibited by NAC. Bcl-2 and HIF-1 $\alpha$ expression levels were increased by hypoxic conditions compared with the control group, but hypoxia-induced expression was inhibited by NAC. ${ }^{*} \mathrm{P}<0.05 ;{ }^{*} \mathrm{P}<0.01$. SIRT1, sirtuin $1 ; \mathrm{NAC}, \mathrm{N}$-acetylcysteine; HIF-1 $\alpha$, hypoxia-inducible factor-1 $\alpha$; p, phosphorylated.
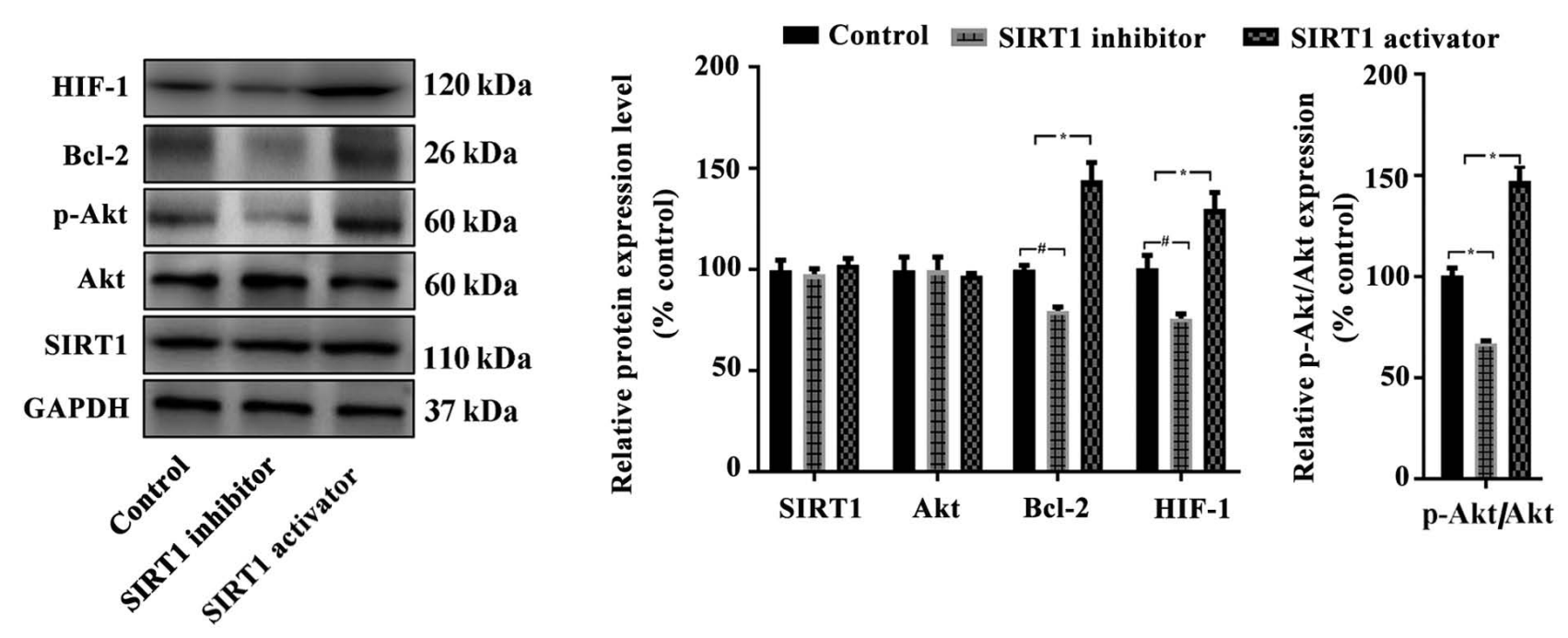

Figure 2. SIRT1 activates Akt and its downstream signaling pathway. Compared with the control group, SIRT1 activator promoted Akt phosphorylation and increased the expression of Bcl-2 and HIF- $1 \alpha$, whereas SIRT1 inhibitor displayed the opposite effect. ${ }^{*} \mathrm{P}<0.05$; ${ }^{*} \mathrm{P}<0.01$. SIRT1, sirtuin 1 ; HIF-1 $\alpha$, hypoxia-inducible factor-1 $\alpha$; p, phosphorylated.

Data were analyzed using FlowJo software (version 7.6.5; FlowJo LLC).

Cell proliferation assay. Cells were seeded $\left(5 \times 10^{3}\right.$ cells/well) into 96 -well plates and cultured overnight at $37^{\circ} \mathrm{C}$ to attach. Cells were maintained under hypoxic or normal conditions for $72 \mathrm{~h}$. Subsequently, cell proliferation was assessed using a WST-1 assay (Roche Diagnostics) according to the manufacturer's protocol. The absorbance of each well was measured at a wavelength of $440 \mathrm{~nm}$ using a multimode plate reader.

siRNA transfection. Cells were seeded $\left(1 \times 10^{5}\right.$ cells/well) into 12-well culture plates and transfected with $40 \mathrm{nM}$ SIRT1 siRNA (sense, 5'-ACUUUGCUGUAACCCUGUA(dTdT)-3' and antisense, 5'-UACAGGGUUACAGCAAAGU(dTdT)-3'.) or scrambled siRNA (sense, 5'-UUCUCCGAACGUGUC ACGU(dTdT)-3' or antisense, 5'-AGGUGACACGUUGGG AGAA(dTdT)-3') (Santa Cruz Biotechnology, Inc.) using Lipofectamine ${ }^{\circledR} 2000$ (Invitrogen; Thermo Fisher Scientific, Inc.) according to the manufacturer's instructions. At $24 \mathrm{~h}$ post-transfection, western blotting was performed to assess transfection efficiency and cells were used for subsequent experiments.

Statistical analysis. All experiments were performed in triplicate. Data were analyzed and illustrated using $\mathrm{R}$ (version 3.6.2; https://www.r-project.org/). Data are presented as the mean \pm SEM. Comparisons between two groups were 

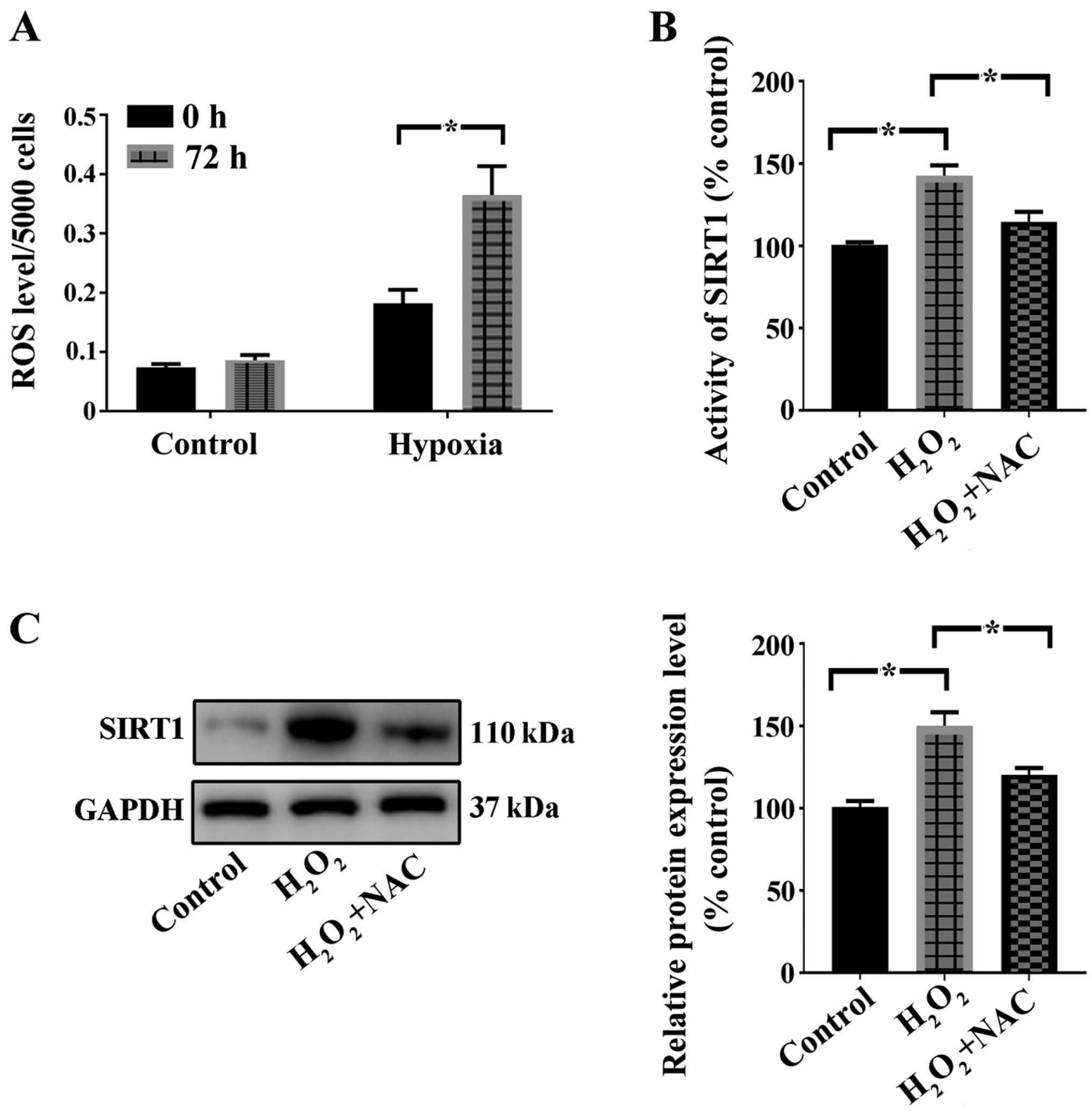

Figure 3. Hypoxia increases SIRT1 expression by inducing ROS generation in cells. (A) ROS levels in cells were increased under hypoxic conditions for $72 \mathrm{~h}$ compared with $0 \mathrm{~h}$. (B) SIRT1 enzyme activity assay. (C) SIRT1 protein expression in cells following treatment with $\mathrm{H}_{2} \mathrm{O}_{2}(1 \mathrm{mM})$ for 72 h. $\mathrm{H}_{2} \mathrm{O}_{2}$-induced SIRT1 activity was blocked by NAC (5 mM). "P<0.05 SIRT1, sirtuin 1; ROS, reactive oxygen species; NAC, N-acetylcysteine.

analyzed using the Student's t-test. Comparisons among multiple groups were analyzed using one-way ANOVA followed by Tukey's post hoc test. $\mathrm{P}<0.05$ was considered to indicate a statistically significant difference.

\section{Results}

SIRT1 expression and the PI3K/Akt/mTOR signaling pathway are upregulated in pulmonary artery endothelial cells under hypoxic conditions. The results indicated that hypoxia significantly increased the expression of SIRT1 in HPAECs in vitro compared with the control group (Fig. 1A). In addition, HIF- $1 \alpha$ is involved in the pathogenesis of PAH and is also a downstream factor of the PI3K/Akt/mTOR signaling pathway (22). The results suggested that hypoxia activated the PI3K/Akt/mTOR signaling pathway, as indicated by significantly increased levels of phosphorylated Akt in the hypoxia group compared with the control group, and significantly increased HIF-1 $\alpha$ expression levels in pulmonary vascular endothelial cells compared with the control group (Fig. 1B).
Moreover, under hypoxic conditions, treatment with NAC significantly decreased SIRT1 expression levels compared with the hypoxia group (Fig. 1A and B), which indicated that hypoxia-induced activation of the Akt signaling pathway could be blocked by NAC.

Hypoxia-induced SIRT1 activates the Akt signaling pathway. The present study investigated whether SIRT1 upregulation was associated with activation of the Akt signaling pathway in HPAECs. The results indicated that SIRT1 activator activated the Akt signaling pathway, as indicated by increased phosphorylation levels of Akt compared with the control group, which was reversed by SIRT1 inhibitor (Fig. 2). Moreover, Bcl-2 (23) and HIF-1 (24) are downstream molecules of the Akt/mTOR signaling pathway. The results also suggested that Bcl-2 and HIF-1 $\alpha$ expression levels were significantly increased in the SIRT1 activator group compared with the control group. By contrast, SIRT1 inhibitor significantly decreased the expression levels of Bcl-2 and HIF-1 $\alpha$ compared with the control group (Fig. 2). 

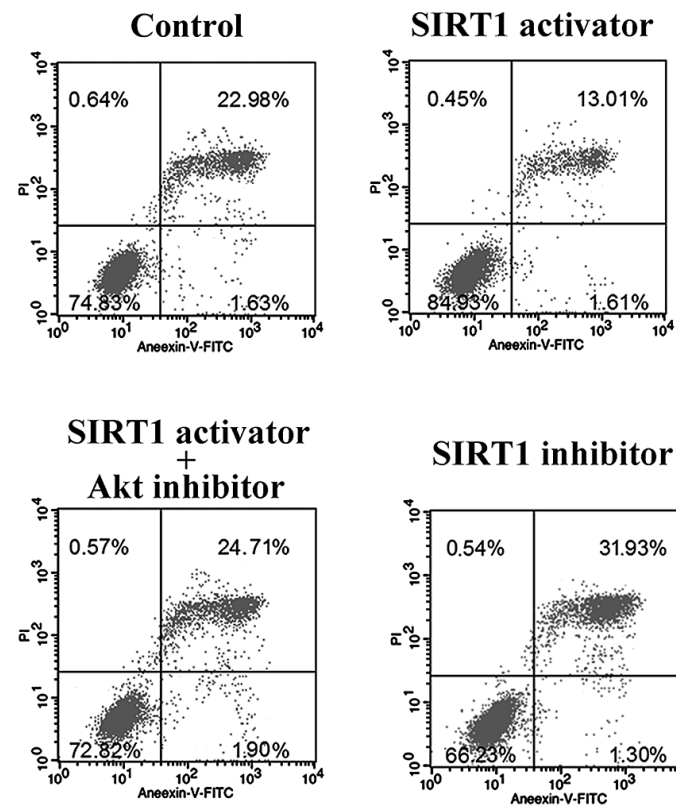

\section{SIRT1 inhibitor}

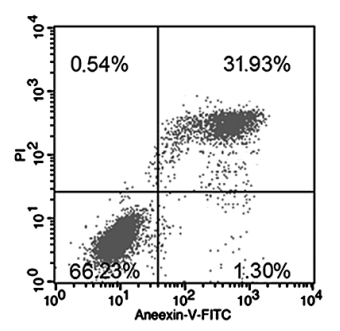

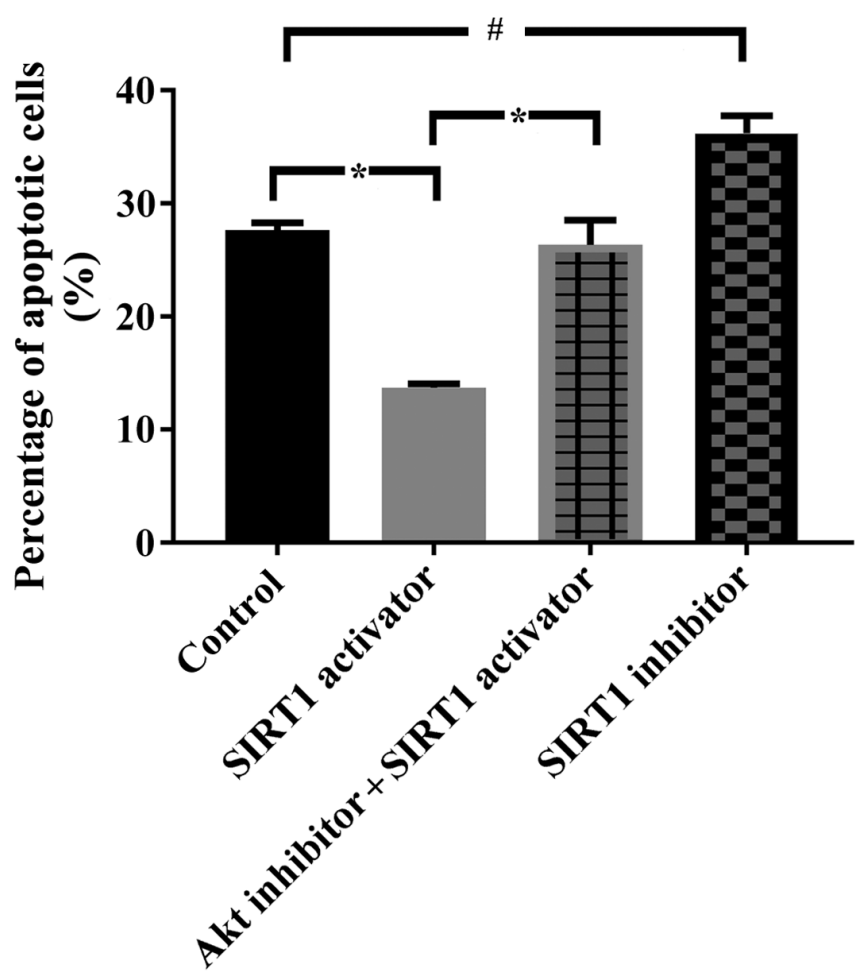

Figure 4. SIRT1 prevents endothelial cell apoptosis under hypoxic conditions in vitro. Compared with the control group, hypoxia treatment promoted cell apoptosis. The proapoptotic effect of hypoxia was attenuated by SIRT1 activator but enhanced by SIRT1 inhibitor. "P $<0.05$; ${ }^{\text {P }}<0.01$. SIRT1, sirtuin 1; PI, propidium iodide.

Moreover, the SIRT1 inhibitor and activator did not alter SIRT-1 expression levels, because the activator and inhibitor blocked the deacetylase activity of SIRT1 rather than altering SIRT1 expression levels.

ROS production promotes SIRT1 expression. Following culture under hypoxic conditions for $72 \mathrm{~h}$, the generation of cellular ROS by HPAECs was assessed. The results indicated that culture for $72 \mathrm{~h}$ in hypoxic conditions significantly increased ROS levels compared with the control group $(0 \mathrm{~h}$; Fig. 3A). Therefore, ROS production may serve as an explanation for increased SIRT1 expression under hypoxic conditions.

Cells treated with $\mathrm{H}_{2} \mathrm{O}_{2}$ (a type of ROS) displayed significantly increased SIRT1 activity and expression levels compared with the control group (Fig. 3B and C). $\mathrm{H}_{2} \mathrm{O}_{2}$-mediated upregulation of SIRT1 activity and expression was inhibited by the anti-ROS reagent NAC (Fig. 3B and C). Therefore, the results suggested that hypoxic conditions could induce ROS generation, which increases SIRT1 expression and its downstream signaling pathway.

SIRT1 promotes cell proliferation and inhibits cell apoptosis via the Akt signaling pathway. To investigate the role of SIRT1 in apoptosis, cells were cultured under hypoxic conditions for $72 \mathrm{~h}$ in the presence of SIRT1 activator, SIRT1 inhibitor and Akt antagonist. Compared with the control group, SIRT1 inhibitor significantly increased the level of apoptosis, whereas SIRT1 activator significantly decreased the level of apoptosis (Fig. 4). The Akt antagonist inhibited the anti-apoptotic effect of SIRT1, which indicated that Akt antagonist alleviated the anti-apoptotic effect of the SIRT1 activator.
Subsequently, the effect of SIRT1 on cell proliferation was investigated. SIRT1 activator significantly increased cell proliferation compared with the control group, an effect that was reversed by the Akt antagonist. SIRT1 inhibitor significantly decreased cell proliferation compared with the control group (Fig. 5A). SIRT1 was knocked down using an siRNA, and the results indicated that cell proliferation was significantly decreased in the siRNA group compared with the scramble control group (Fig. 5B).

In addition, the results indicated that SIRT1 inhibitor significantly decreased cell proliferation and increased cell apoptosis in a dose-dependent manner compared with the control group (Fig. S1).

\section{Discussion}

The present study suggested that, compared with control cells, SIRT1 expression was increased in HPAECs under hypoxic conditions as a prosurvival gene expression profile triggered by chronic hypoxia. SIRT1 promoted cell proliferation and prevented cell apoptosis via regulation of the Akt signaling pathway. In addition, the present study indicated that SIRT1 expression was induced by ROS generation under hypoxic conditions. Collectively, the results of the present study furthered the current understanding of the role of SIRT1 in endothelial cells of the microvascular system under hypoxic conditions.

Hypoxic conditions can induce pathological alterations in endothelial cells of the vascular system. Under hypoxic conditions, ROS generation increases, overwhelming the antioxidant systems, which consist of stable oxidants, such as $\mathrm{H}_{2} \mathrm{O}_{2}$, and unstable free radicals, such as superoxide 

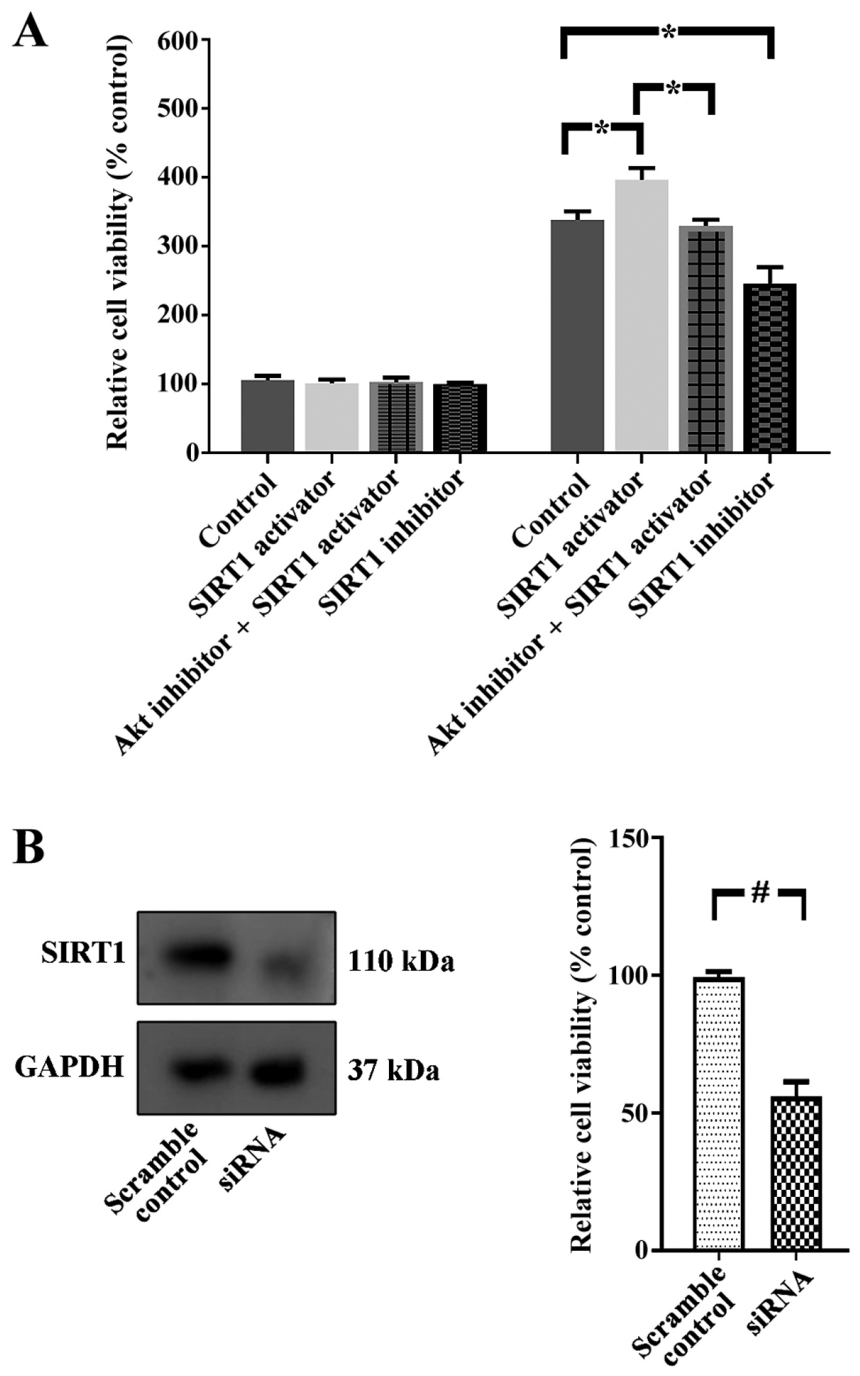

Figure 5. SIRT1 promotes endothelial cell proliferation in vitro. (A) Compared with the control group, SIRT1 activator increased cell proliferation, whereas SIRT1 inhibitor inhibited cell proliferation. In addition, Akt antagonist alleviated SIRT1 activator-induced proliferation. (B) SIRT1 knockdown decreased cell proliferation compared with the scramble control group. ${ }^{*} \mathrm{P}<0.05 ;{ }^{\#} \mathrm{P}<0.01$. SIRT1, sirtuin 1; siRNA, small interfering RNA.

anion, nitric oxide, hydroxyl moiety and hypochlorite (25). Demarco et al (26) suggested that ROS are continuously generated in both endothelial and smooth muscle cells of the pulmonary vascular system under normal physiological conditions, which then participate in cellular events and regulate cell bio-behavior (27). However, excess ROS generation can induce DNA, lipid and peptides oxidation, which damages cells and induces tissue dysfunction, contributing to the pathogenesis of a number of diseases, such as pulmonary and systemic hypertension (28), heart failure (29) and ventricular hypertrophy (30). Furthermore, ROS may promote smooth muscle and endothelial cell vasoconstriction and proliferation in the microvascular system, which induces vascular remodeling and contributes to the pathogenesis of PAH (31). For instance, in mouse models of hypoxia-induced PAH, intrapulmonary artery ROS levels are elevated $(32,33)$. Moreover, exposure to hypoxia increases ROS generation, xanthine oxidase levels and enzyme activities of pulmonary artery endothelial cells in mice (34). Therefore, the generation of ROS may induce expression alterations to genes and signaling pathways that contribute to the pathogenesis of PAH, including SIRT1.

Ruan et al (12) demonstrated that ROS generation induced by androgen deprivation therapy promoted SIRT1 expression in prostate cancer. In another study, Hasegawa et al (35) suggested that $\mathrm{H}_{2} \mathrm{O}_{2}$ can promote the expression of SIRT1 in renal tubular epithelial cells. In the present study, the results indicated that increased SIRT1 expression may be induced by cellular ROS generation, whereas NAC treatment alleviated SIRT1 upregulation in cells. It was hypothesized that the regulatory effect of NAC on SIRT1 expression may be attributed to its anti-ROS role in cells. However, NAC has multiple roles in cells, such as participation in cell apoptosis (36) and antibody-dependent cellular cytotoxicity (37). Therefore, the relationship between ROS and SIRT1 expression requires further investigation.

SIRT1 is a nicotinamide adenine dinucleotide ${ }^{+}$-dependent histone deacetylase (38) that can regulate cell apoptosis, migration and proliferation (39). The present study suggested that SIRT1 activated the Akt signaling pathway in vascular endothelial cells. Akt/mTOR is a classic signaling pathway that is regulated by SIRT1 (40). Under basal conditions, Akt is acetylated in various tissues, including the heart, liver, brain and skeletal muscle, which suppresses Akt activity (41). Deacetylation of lysines by SIRT1 is necessary for the binding of Akt to phosphatidylinositol (3-5)-trisphosphate (PIP3), and for its membrane localization and activation (42). Activated Akt then phosphorylates mTOR and activates its downstream signaling pathway. Sundaresan et al (42) suggested that SIRT1 enhances the binding of Akt to PIP3 and promotes their activation via deacetylation in cancer and cardiac hypertrophy, whereas SIRT1 knockout in mice reduces cardiac hypertrophy. Furthermore, the SIRT1 and Akt signaling pathways serve a cardinal role in the process of angiogenesis, and SIRT1-deficient mice display an impaired ability to develop new blood vessels in response to angiogenic signals (43). In addition, decreased SIRT1 expression is observed in aging hearts (44), where it downregulates the activity of the Akt signaling pathway and induces cell apoptosis (45).

$\mathrm{Akt} / \mathrm{mTOR}$ is an important intracellular signaling pathway for regulating multiple events in cells (46). Increasing evidence has demonstrated that the Akt/mTOR signaling pathway is activated and involved in PAH via vasoconstriction and remodeling (47). Furthermore, blocking the Akt/mTOR signaling pathway reverses PAH in animal models $(48,49)$. The present study indicated that SIRT1 upregulated Akt/mTOR in endothelial cells under hypoxic conditions. Moreover, the results suggested that SIRT1 expression regulated HIF-1 $\alpha$ protein levels as a downstream molecule of the Akt/mTOR signaling pathway. HIF-1 contains two subunits, HIF-1 $\alpha$ (oxygen-sensitive) and HIF-1 $\beta$ (constitutive subunit), and its expression is activated by the restriction of oxygen supply (50). HIF-1 is another critical molecule in PAH. Abnormalities in HIF-1 that underlie PAH are observed in the rat model and blocking the expression of HIF-1 increases the level of voltage-gated potassium channel expression, thereby reducing pathologic alterations in PAH (22).

The present study had a number of limitations. In addition to endothelial cells, smooth muscle and adventitial cells may contribute to the pathogenesis of PAH. Zurlo et al (15) 
suggested that SIRT1 can regulate human pulmonary artery smooth muscle cell proliferation, serving a role in $\mathrm{PAH}$ development. Adventitia serves as another key regulator of pulmonary vascular wall function and structure (51). Burke et al (51) suggested that hypoxia induced vascular inflammation, which increased the thickness and inflammatory cells in the adventitia of the rat pulmonary artery. Therefore, the role of SIRT1 in smooth muscle and adventitial cells under hypoxic conditions requires further investigation. Furthermore, the present study did not use an animal model to investigate alterations in SIRT1 expression in PAH. The mouse model of PAH has been widely used in research, and the role of SIRT1 in vascular endothelial cells in vivo needs to be explored. For example, application of hypoxia and Sugen is a method commonly used to trigger pulmonary hypertension (52). Further research on SIRT1 needs to be performed in a mouse model to prove its translational value in the clinical setting. The administration of SIRT1 inhibitor in vivo has been reported by previous studies. Huang et al (53) suggested that a treatment-selective SIRT1 inhibitor with EX-527 attenuated lipopolysaccharide-induced histological abnormalities in lung tissue in mice. Furthermore, certain studies have used SIRT1 inhibitor to treat human Huntington disease. For example, the SIRT1 inhibitor selisistat has been used to treat Huntington's disease $(54,55)$ in clinical trials, proving the safety and tolerance of SIRT1 inhibitor.

Collectively, the present study indicated that ROS generation promoted SIRT1 expression under hypoxic conditions, which activated the Akt signaling pathway to promote cell proliferation and inhibit cell apoptosis in microvascular endothelial cells. Therefore, inhibition of SIRT1 may serve as a potential therapeutic strategy against hypoxia in vascular endothelial cells.

\section{Acknowledgements}

Not applicable.

\section{Funding}

This study was supported by the Colleges and Universities in Hebei Province Science and Technology Research Project (grant no. QN2019189).

\section{Availability of data and materials}

The datasets used and/or analyzed during the present study are available from the corresponding author on reasonable request.

\section{Authors' contributions}

LX and LR designed and performed experiments, analyzed the data and wrote the manuscript. XY, DZ and HY performed experiments. QL and CY contributed to study design and wrote the manuscript. All authors read and approved the final manuscript.

\section{Ethics approval and consent to participate}

Not applicable.

\section{Patient consent for publication}

Not applicable.

\section{Competing interests}

The authors declare that they have no competing interests.

\section{References}

1. Montani D, Günther S, Dorfmüller P,Perros F, Girerd B, Garcia G, Jaïs X, Savale L, Artaud-Macari E, Price LC, et al: Pulmonary arterial hypertension. Orphanet J Rare Dis 8: 97, 2013.

2. Tuder RM, Marecki JC, Richter A, Fijalkowska I and Flores S: Pathology of pulmonary hypertension. Clin Chest Med 28: 23-42, vii, 2007.

3. Budhiraja R, Tuder RM and Hassoun PM: Endothelial dysfunction in pulmonary hypertension. Circulation 109: 159-165, 2004.

4. Upton PD, Davies RJ, Tajsic T and Morrell NW: Transforming growth factor- $\beta(1)$ represses bone morphogenetic protein-mediated Smad signaling in pulmonary artery smooth muscle cells via Smad3. Am J Respir Cell Mol Biol 49: 1135-1145, 2013.

5. Rol N, Kurakula KB, Happé C, Bogaard HJ and Goumans MJ: TGF- $\beta$ and BMPR 2 signaling in PAH: Two black sheep in one family. Int J Mol Sci 19: 2585, 2018.

6. Wong WK, Knowles JA and Morse JH: Bone morphogenetic protein receptor type II C-terminus interacts with $\mathrm{c}-\mathrm{Src}$ : Implication for a role in pulmonary arterial hypertension. Am J Respir Cell Mol Biol 33: 438-446, 2005.

7. Liu D and Morrell NW: Genetics and the molecular pathogenesis of pulmonary arterial hypertension. Curr Hypertens Rep 15: 632-637, 2013.

8. Tuder RM: Pulmonary vascular remodeling in pulmonary hypertension. Cell Tissue Res 367: 643-649, 2017.

9. Stenmark KR, Fagan KA and Frid MG: Hypoxia-induced pulmonary vascular remodeling: Cellular and molecular mechanisms. Circ Res 99: 675-691, 2006.

10. Wong CM, Bansal G, Pavlickova L, Marcocci L and Suzuki YJ: Reactive oxygen species and antioxidants in pulmonary hypertension. Antioxid Redox Signal 18: 1789-1796, 2013.

11. Salminen A, Kaarniranta K and Kauppinen A: Crosstalk between oxidative stress and SIRT1: Impact on the aging process. Int $\mathbf{J}$ Mol Sci 14: 3834-3859, 2013.

12. Ruan L, Wang L, Wang X, He M and Yao X: SIRT1 contributes to neuroendocrine differentiation of prostate cancer. Oncotarget 9: 2002-2016, 2017

13. Martinez-Redondo P and Vaquero A: The diversity of histone versus nonhistone sirtuin substrates. Genes Cancer 4: 148-163, 2013.

14. Chen PI, Cao A, Miyagawa K, Tojais NF, Hennigs JK, Li CG, Sweeney NM, Inglis AS, Wang L, Li D, et al: Amphetamines promote mitochondrial dysfunction and DNA damage in pulmonary hypertension. JCI Insight 2: e90427, 2017.

15. Zurlo G, Piquereau J, Moulin M, Pires Da Silva J, Gressette M, Ranchoux B, Garnier A, Ventura-Clapier R, Fadel E, Humbert M, et al: Sirtuin 1 regulates pulmonary artery smooth muscle cell proliferation: Role in pulmonary arterial hypertension. J Hypertens 36: 1164-1177, 2018.

16. Peck B, Chen CY, Ho KK, Di Fruscia P, Myatt SS, Coombes RC, Fuchter MJ, Hsiao CD and Lam EW: SIRT inhibitors induce cell death and p53 acetylation through targeting both SIRT1 and SIRT2. Mol Cancer Ther 9: 844-855, 2010.

17. Sefton EC, Qiang W, Serna V, Kurita T, Wei JJ, Chakravarti D and Kim JJ: MK-2206, an AKT inhibitor, promotes caspase-independent cell death and inhibits leiomyoma growth. Endocrinology 154: 4046-4057, 2013.

18. Shiota M, Yokomizo A, Tada Y, Inokuchi J, Kashiwagi E, Masubuchi D, Eto M, Uchiumi T and Naito S: Castration resistance of prostate cancer cells caused by castration-induced oxidative stress through Twist 1 and androgen receptor overexpression. Oncogene 29: 237-250, 2010.

19. Kang BY, Kleinhenz JM, Murphy TC and Hart CM: The PPAR $\gamma$ ligand rosiglitazone attenuates hypoxia-induced endothelin signaling in vitro and in vivo. Am J Physiol Lung Cell Mol Physiol 301: L881-L891, 2011. 
20. Green DE,Murphy TC,Kang BY,KleinhenzJM,Szyndralewiez C Page P, Sutliff RL and Hart CM: The Nox4 inhibitor GKT137831 attenuates hypoxia-induced pulmonary vascular cell proliferation. Am J Respir Cell Mol Biol 47: 718-726, 2012.

21. Livak KJ and Schmittgen TD: Analysis of relative gene expression data using real-time quantitative PCR and the 2(-Delta Delta $\mathrm{C}(\mathrm{T}))$ method. Methods 25: 402-408, 2001.

22. Bonnet S, Michelakis ED, Porter CJ, Andrade-Navarro MA, Thébaud B, Bonnet S, Haromy A, Harry G, Moudgil R, McMurtry MS, et al: An abnormal mitochondrial-hypoxia inducible factor-1alpha-Kv channel pathway disrupts oxygen sensing and triggers pulmonary arterial hypertension in fawn hooded rats: Similarities to human pulmonary arterial hypertension. Circulation 113: 2630-2641, 2006.

23. Kennedy SG, Wagner AJ, Conzen SD, Jordán J, Bellacosa A, Tsichlis PN and Hay N: The PI 3-kinase/Akt signaling pathway delivers an anti-apoptotic signal. Genes Dev 11: 701-713, 1997.

24. Kazi AA, Molitoris KH and Koos RD: Estrogen rapidly activates the PI3K/AKT pathway and hypoxia-inducible factor 1 and induces vascular endothelial growth factor A expression in luminal epithelial cells of the rat uterus. Biol Reprod 81: 378-387, 2009.

25. Phaniendra A, Jestadi DB and Periyasamy L: Free radicals: Properties, sources, targets, and their implication in various diseases. Indian J Clin Biochem 30: 11-26, 2015.

26. Demarco VG, Whaley-Connell AT, Sowers JR, Habibi J and Dellsperger KC: Contribution of oxidative stress to pulmonary arterial hypertension. World J Cardiol 2: 316-324, 2010.

27. Migliaccio E, Giorgio M and Pelicci PG: Apoptosis and aging: Role of p66Shc redox protein. Antioxid Redox Signal 8: 600-608, 2006.

28. Zangar RC, Davydov DR and Verma S: Mechanisms that regulate production of reactive oxygen species by cytochrome $\mathrm{P} 450$. Toxicol Appl Pharmacol 199: 316-331, 2004.

29. Circu ML, Moyer MP, Harrison L and Aw TY: Contribution of glutathione status to oxidant-induced mitochondrial DNA damage in colonic epithelial cells. Free Radic Biol Med 47: 1190-1198, 2009.

30. Rachek LI, Yuzefovych LV, Ledoux SP, Julie NL and Wilson GL: Troglitazone, but not rosiglitazone, damages mitochondrial DNA and induces mitochondrial dysfunction and cell death in human hepatocytes. Toxicol Appl Pharmacol 240: 348-354, 2009.

31. Wedgwood S and Black SM: Role of reactive oxygen species in vascular remodeling associated with pulmonary hypertension. Antioxid Redox Signal 5: 759-769, 2003.

32. Kemp M, Go YM and Jones DP: Nonequilibrium thermodynamics of thiol/disulfide redox systems: A perspective on redox systems biology. Free Radic Biol Med 44: 921-937, 2008.

33. Go YM and Jones DP: Redox compartmentalization in eukaryotic cells. Biochim Biophys Acta 1780: 1273-1290, 2008.

34. Ekshyyan O and Aw TY: Decreased susceptibility of differentiated PC12 cells to oxidative challenge: Relationship to cellular redox and expression of apoptotic protease activator factor-1. Cell Death Differ 12: 1066-1077, 2005.

35. Hasegawa K, Wakino S, Yoshioka K, Tatematsu S, Hara Y, Minakuchi $\mathrm{H}$, Washida N, Tokuyama $\mathrm{H}$, Hayashi $\mathrm{K}$ and Itoh $\mathrm{H}$ : Sirt1 protects against oxidative stress-induced renal tubular cell apoptosis by the bidirectional regulation of catalase expression Biochem Biophys Res Commun 372: 51-56, 2008.

36. Sancho-Martinez SM,Prieto-Garcia L, Prieto M,Fuentes-Calvo I López-Novoa JM, Morales AI, Martínez-Salgado C and López-Hernández FJ: $\mathrm{N}$-acetylcysteine transforms necrosis into apoptosis and affords tailored protection from cisplatin cytotoxicity. Toxicol Appl Pharmacol 349: 83-93, 2018.

37. Roberts RL, Aroda VR and Ank BJ: N-acetylcysteine enhances antibody-dependent cellular cytotoxicity in neutrophils and mononuclear cells from healthy adults and human immunodeficiency virus-infected patients. J Infect Dis 172: 1492-1502, 1995

38. Tanno M, Sakamoto J, Miura T, Shimamoto K and Horio $\mathrm{Y}$ : Nucleocytoplasmic shuttling of the NAD+-dependent histone deacetylase SIRT1. J Biol Chem 282: 6823-6832, 2007.

39. Yamamoto H, Schoonjans K and Auwerx J: Sirtuin functions in health and disease. Mol Endocrinol 21: 1745-1755, 2007.
40. Jin X, Wei Y, Xu F, Zhao M, Dai K, Shen R, Yang S and Zhang N: SIRT1 promotes formation of breast cancer through modulating Akt activity. J Cancer 9: 2012-2023, 2018.

41. Pillai VB, Sundaresan NR and Gupta MP: Regulation of Akt signaling by sirtuins: Its implication in cardiac hypertrophy and aging. Circ Res 114: 368-378, 2014.

42. Sundaresan NR, Pillai VB, Wolfgeher D, Samant S, Vasudevan P, Parekh V, Raghuraman H, Cunningham JM, Gupta M and Gupta MP: The deacetylase SIRT1 promotes membrane localization and activation of Akt and PDK1 during tumorigenesis and cardiac hypertrophy. Sci Signal 4: ra46, 2011.

43. Potente M, Ghaeni L, Baldessari D, Mostoslavsky R, Rossig L, Dequiedt F, Haendeler J, Mione M, Dejana E, Alt FW, et al: SIRT1 controls endothelial angiogenic functions during vascular growth. Genes Dev 21: 2644-2658, 2007.

44. Tong C, Morrison A, Mattison S, Qian S, Bryniarski M, Rankin B, Wang J, Thomas DP and Li J: Impaired SIRT1 nucleocytoplasmic shuttling in the senescent heart during ischemic stress. FASEB J 27: 4332-4342, 2013. Shiraishi I, Melendez J, Ahn Y, Skavdahl M, Murphy E, Welch S, Schaefer E, Walsh K, Rosenzweig A, Torella D, et al: Nuclear targeting of Akt enhances kinase activity and survival of cardiomyocytes. Circ Res 94: 884-891, 2004

45. Shiraishi I, Melendez J, Ahn Y, et al.: Nuclear targeting of Akt enhances kinase activity and survival of cardiomyocytes. Circ Res 94: 884-891, 2004

46. Saxton RA and Sabatini DM: mTOR signaling in growth, metabolism, and disease. Cell 169: 361-371, 2017.

47. Paddenberg R, Stieger P, von Lilien AL, Faulhammer P, Goldenberg A, Tillmanns HH, Kummer W and Braun-Dullaeus RC: Rapamycin attenuates hypoxia-induced pulmonary vascular remodeling and right ventricular hypertrophy in mice. Respir Res 8: 15, 2007.

48. Huang S, Zhu X, Huang W, He Y, Pang L, Lan X, Shui X, Chen Y, Chen C and Lei W: Quercetin inhibits pulmonary arterial endothelial cell transdifferentiation possibly by Akt and Erk1/2 pathways. Biomed Res Int 2017: 6147294, 2017.

49. Huang X, Wu P, Huang F, Xu M, Chen M, Huang K, Li GP, Xu M, Yao D and Wang L: Baicalin attenuates chronic hypoxia-induced pulmonary hypertension via adenosine A2A receptor-induced SDF-1/CXCR4/PI3K/AKT signaling. J Biomed Sci 24: 52, 2017.

50. Semenza GL: Life with oxygen. Science 318: 62-64, 2007.

51. Burke DL, Frid MG, Kunrath CL, Karoor V, Anwar A, Wagner BD, Strassheim D and Stenmark KR: Sustained hypoxia promotes the development of a pulmonary artery-specific chronic inflammatory microenvironment. Am J Physiol Lung Cell Mol Physiol 297: L238-L250, 2009.

52. Vitali SH, Hansmann G, Rose C, Fernandez-Gonzalez A, Scheid A, Mitsialis SA and Kourembanas S: The Sugen 5416/hypoxia mouse model of pulmonary hypertension revisited: Long-term follow-up. Pulm Circ 4: 619-629, 2014.

53. Huang J, Tian R, Yang Y, Jiang R, Dai J, Tang L and Zhang L: The SIRT1 inhibitor EX-527 suppresses mTOR activation and alleviates acute lung injury in mice with endotoxiemia. Innate Immun 23: 678-686, 2017.

54. Süssmuth SD, Haider S, Landwehrmeyer GB, Farmer R, Frost C, Tripepi G, Andersen CA, Di Bacco M, Lamanna C, Diodato $\mathrm{E}$, et al: An exploratory double-blind, randomized clinical trial with selisistat, a SirT1 inhibitor, in patients with Huntington's disease. Br J Clin Pharmacol 79: 465-476, 2015

55. Westerberg G, Chiesa JA, Andersen CA, Diamanti D, Magnoni L, Pollio G, Darpo B and Zhou M: Safety, pharmacokinetics, pharmacogenomics and QT concentration-effect modelling of the SirT1 inhibitor selisistat in healthy volunteers. Br J Clin Pharmacol 79: 477-491, 2015.

This work is licensed under a Creative Commons Attribution-NonCommercial-NoDerivatives 4.0 International (CC BY-NC-ND 4.0) License. 